\title{
PLANT PROTECTION AND ECO-LABELLING OF PRIMARY PRODUCTS
}

\author{
N.J. BALL \\ Tesco, Produce Dept., Delamare Road, Cheshunt, Herts, EN8 9SL
}

\begin{abstract}
It is clear that consumers are anxious about residues of agrochemicals in food, their environmental impact and their safety in usage. It is also clear that lessening dependence on agrochemicals to reduce risk, and improve efficiency of farming businesses is desirable. The question for many growers is how to convey the meaning of successful integrated crop management to their advantage. Eco-labelling is one option, attempted in Europe and the US, but research has shown little understanding by consumers. Consumers can define 'organic', but to create awareness of the benefits of integrated crop management systems, more exposure is needed than logos on labels.
\end{abstract}

Keywords: consumers, agrochemicals, integrated, eco-labelling

\section{INTRODUCTION}

The components of the fresh produce business are like any other, with producers, sellers and consumers. As with any business, normal market forces apply: the objectives of producing a product, establishing, maintaining and growing a market can ultimately only be successful if the producer has a clear understanding of the customer and the customer's power to choose the goods they purchase. Unfortunately, the fresh produce industry has a poor record for understanding the customer, and in many countries has failed to increase its share of the overall food market. In developed countries the competition within the food business is intense, and the fresh produce sector, with all its natural advantages, has all too often found itself in a defensive position due to consumers underlying anxiety about methods of production. If producers wish to increase consumption of fresh produce, they must understand what their customers want, what motivates them to buy and what barriers exist to them increasing consumption.

\section{CUSTOMERS OF PRIMARY PRODUCERS}

The main customers of the primary producer are the retailer and the final consumer. In some circumstances a marketing organisation may also be included, particularly as a representative in export markets. However, the marketing organisation normally has the same responsibilities and customers as the primary producer.

As a customer, the retailer wants a good product to sell, continuity of supply, consistency and efficiency, responsiveness, confidence in the product and production, and a good relationship with the supplier. A retailer's confidence in a supplying grower group is a valuable asset as it may make the difference in choosing between suppliers in a competitive market.

The final consumer wants quality, value, choice, availability, confidence in the product, a guilt-free conscience and a healthy diet. The precise ranking of these requirements depends on the cultural and financial circumstances of the consumer, but all are influenced by similar factors in any market.

Fresh produce purchases by consumers are further influenced by the following:

- Position of a product in the diet: staple or luxury, traditional or ingredient

- Health benefit: fibre, nutrient and vitamin content

- Taste: degree of enjoyment

- Convenience: ease of use 
- Good associations: influenced by media, education and information

- Good retailing: emphasising the attractiveness of fresh produce

Barriers to purchasing fresh produce, and increasing consumption, are:

- Poorquality

- Poor value

- Ignorance of usage

- Preference for other foods: snacks, fast foods

- Lack of confidence in product and production, safety and environment.

- $\quad$ Poor retailing

Primary producers have direct influence over quality and confidence in the product through the production methods they choose and their skill in growing the crop. The produce industry as a whole, perhaps with assistance from Government, should be responsible for creating good associations and re-enforcing the health benefits of fresh produce. The responsibility for good retailing, creating value and offering choice lies with the retailer and the general market conditions.

\section{CONSUMER CONFIDENCE}

The factors affecting consumer confidence in fresh produce are well known, but rarely based on objective scientific evidence. The associations of agriculture, and therefore many primary foods, with poisonous chemicals, pollution, over-extraction of water, carcinogenic residues, organochlorines and phosphates, pesticide container dumps, soil erosion, exploitative agri-business, exploitation of labour and destruction of habitats are all damaging to the industry.

The most powerful images in the minds of the consumer are those of pesticides. Since the research on persistence of organochlorines, awareness of pesticides has gradually increased, aided and abetted by numerous media scares, both real and imagined. There has been an abundance of media comment, often ill-informed, which promotes anxiety about pesticides in many developed countries. Without doubt, this anxiety is an important barrier to increasing consumption of fresh fruit and vegetables, particularly in less agrarian societies, and should be a significant motivation for change within the agricultural community.

In the context of plant protection and the direct influence of the primary producer on the retailer and consumer, consumers perception of agricultural production methods is all important in formulating their opinions and shaping their decisions. In markets where a lack of confidence exists, opinions have been shaped by negative publicity rather than positive re-enforcement of images of agriculture. Increasing confidence in production requires a better understanding of methods used, as well as removal of negative images. The raising of consumer confidence in agricultural production is essential in the quest for increased consumption, particularly in horticulture.

\section{IMPROVING CONSUMER CONFIDENCE}

When dealing with customer queries about pesticide usage, the minimum response of retailers is to cite the adherence by growers to Government regulations, to approved pesticide label recommendations and to the fact that pesticides generally breakdown over relatively short periods of time. They reiterate the scientifically proven arguments that residues at or below the maximum residue levels (MRL) are safe, and will re-assure customers that products are regularly tested as part of rigorous control procedures. Most retailers will give their suppliers the responsibility of ensuring MRLs are not exceeded on products, and some retailers will employ technologists to ensure that suppliers are keeping the records that prove existence of their own control systems with the growers they represent.

For many years, this approach has been sufficient to give customers some confidence that retailers are protecting their interests, but it is not a positive process and does nothing to counteract persistent media coverage and the low level anxiety felt by many people. Agriculture needs to take a more positive approach to gaining and improving consumer confidence and must integrate public concern with viable production techniques.

The essential components to addressing these issues are: 
- Growing in the safest, most environmentally friendly and ethical manner possible

- Proving the integrity of the production systems

- Informing consumers about the safety and sustainability of production systems

It is clear that integrated crop management (ICM) is the correct development for growers, but total consumer confidence can only be assured if this is applied in an holistic manner by reducing environmental impact of farming and guaranteeing safety of products.

\section{IMPROVED AGRICULTURAL SYSTEMS}

The motivation for growers to change their methods of production are numerous. Many of the developments in plant protection have been generated by agronomic factors, particularly in respect to resistance to agrochemicals and safety of workers. These have resulted in well documented research into, and adoption of, biological control agents and integrated control systems.

Similar momentum for change has resulted from the realisation that integrated control systems can be more efficient, although economic savings are dependent on the crop in question. In addition, the evolution of plant protection systems is an inevitable process as growers pride themselves in achieving greater attention to detail, and the industry becomes more knowledgeable about crop and pest and disease dynamics.

It is also interesting to consider how much change has taken place due to the influence of consumers and the environmental lobbies, particularly in crops that have not required change for agronomic reasons. This 'consumer' pressure has been a powerful force for change in the industry's approach to plant protection.

It is common to find resistance to adoption of ICM among growers, and they often seek to obtain a premium for the product to justify the effort required for implementation. However, payment of premiums is rare and short-term: of more significance is the longterm security of a growers' market, which can only be guaranteed through customer confidence and satisfaction.

There are many examples throughout the world of growers adopting integrated pest management (IPM) schemes and ICM schemes. However, to the consumer, the concept of these schemes is invariably very difficult to grasp, particularly in relation to organic production.

The variability in the definition and interpretation of IPM and ICM on different crops and in different countries is a major drawback. In addition, the sometimes cynical use of the terms by marketing organisations, attempting to emphasise the integrity of their growers, has been a cause for confusion. To build consumer confidence in production systems, there has to be a defined system, with clear objectives and sufficient scope to address all the issues raised by farming activities. To enable marketing of such a concept, the integrity of schemes must be provable. Consumer trust takes time and effort to establish, but confidence is easily lost.

\section{INTEGRATED CROP MANAGEMENT}

For any individual crop within a group of growers, a region or country, or retailer supply-base, a defined and agreed system of ICM needs to be established and enforced. Elements common to all schemes should include the following:

\section{Usage of chemicals}

Minimising chemical intervention through use of all cultural and biological means available; monitoring of pests and diseases to enable justification of intervention activity; minimising or eliminating pesticide residues on the final product, preferably with a target or guarantee that the consumer can understand.

Safety

Ensuring safety of agricultural workers during all farming activities; training; hygiene.

\section{Use of Natural Resources}

Considered use of water, energy and all materials; recycling of waste products wherever possible.

Protection and Enhancement of the Environment 
Elimination of water, air and soil pollution; safe disposal of non-recyclable waste; encouragement of biodiversity.

\section{Worker Welfare}

Eliminating unethical exploitation of the agricultural work force.

\section{INTEGRITY OF ICM SYSTEMS}

If any defined ICM scheme is to be exposed to the consumer, it must have credibility in the eyes of those consumers and its claims must withstand public scrutiny. Any scheme must prove its existence through accurate recording of the farming activities, which is, in any case, a prerequisite in a well managed business. The ability to ensure "traceability" by linking the product in the carton or bulk package to the accurate records of its production in the field is a vital component of verification.

To give a defined scheme cohesion and vitality within and between its members, some form of verification or audit is necessary. The degree of verification required to ensure credibility in the eyes of the consumer will vary. In some circumstances the approval of a retailer may be sufficient; in others, fully independent verification may be needed to convince a sceptical public. Whatever the market circumstances, it is clearly vital that integrity of a scheme is maintained if exposure to the consumers is to be successful.

\section{ECO-LABELLING AND MARKETING}

Where an all encompassing, verifiable ICM scheme of integrity exists within a distinct grouping of producers, there is potential to sell its benefits to customers and remove some of the barriers to increasing consumption. The methods used to convey the concepts of ICM depend on the level of understanding within the target audience. Giving confidence to larger retailers is relatively easy as their technologists will generally understand ICM, and will be able to judge the integrity of a scheme. In circumstances where a grower group can guarantee total compliance with an ICM scheme, a large retailer will not necessarily require evidence of compliance on the carton or bulk package (eco-labelling). However, for smaller retailers with limited technical resource, or in circumstances where a grower group has only partial compliance, eco-labelling on cartons or bulk packaging may be desirable. The Dutch Butterfly programme is an example of a scheme initially aimed at the retail and wholesale sector rather than the final consumer.

To gain the attention of the final consumer, the marketing methods employed depend on the consumers understanding of the concept of ICM. Eco-labelling of final product is pointless unless this understanding exists, as it will only result in confusion with organic products, and potential association with greater expense and poorer quality. Where a distinction between organic, ICM and conventional production exists in the mind of the consumer, use of logos and symbols at point of sale can be beneficial. However, the design of the symbol must be simple, distinctive and consistent.

The associations that symbols imply are important to consider. In Italy, the use of a ladybird symbol on apples, clearly identified as originating in the Sud-Tirol region, is a good example of eco-labelling working among consumers. The ICM scheme is independently verified in the production areas, and the ability to eco-label generates consumer confidence in a market with some awareness of ICM. But the consumer also knows where the apples are grown, which may be as important in developing trust. The same symbol on citrus from Spain, for example, may not generate the same level of confidence in that market.

To simplify the complexities of these messages to consumers, the retailers' involvement and endorsement is important, particularly in markets where comprehension of ICM is limited or non-existent. In Switzerland, retailer Migros has developed its own brand of ICM-produced fresh produce, and finds it beneficial to market the brand alongside conventional and organically produced products. In UK, retailer Tesco has a similar scheme, but is not directly selling the product as a brand. Instead, the scheme is given exposure to customers through continual reinforcement in "advertorials" and media opportunities, and endorsement by respected non-government organisations. 
Both these retailers have developed directly verifiable ICM schemes within their own supply-base, but generate customer confidence by methods suitable to their particular market.

Where a grower group or producing country has a distinct brand as well as a distinct ICM scheme, there are ample opportunities to improve consumer confidence through combined marketing messages. Association of a well-known brand with the positive images of ICM should be a powerful combination, but, as emphasised through-out this paper, credibility of the ICM scheme remains essential if consumer confidence is to be translated into increase consumption. 